\title{
On the issue of a favorable environment in the "Smart City" development program
}

\author{
Marina A. Vakula ${ }^{1}$ \\ Peoples Friendship University of Russia (RUDN University), Department of Land and Environmental \\ Law of the Law Institute, 6 Miklukho-Maklaya Street, Moscow, 117198, Russian Federation
}

\begin{abstract}
The article examines acute problems of ensuring a favorable environment in urbanized areas. The author pays special attention to the greening of the urban economy by implementing the "Smart City" program's digital technologies. The study rests on research and particular scientific methods of cognition. The dialectical method made it possible to ensure a favorable environment in urban areas and, in conjunction with indicators, assess its quality. The comparative legal method is taken as a basis for identifying general trends in the use of new information technologies to determine the quality of a favorable environment. The article emphases that the implementation of information technology in ensuring a favorable environment contributes to an increase in the effectiveness of measures aimed at protecting it from negative influences. Simultaneously, indications of the effectiveness of the implementation of promising programs, including the Smart City program, use virtual indicators that are not accompanied by indicators that allow assessing the degree of environmental friendliness in quantitative terms. The article contains suggestions for improving the mechanism for protecting a favorable environment in the "Smart City" development program.
\end{abstract}

\section{Introduction}

The mechanism for ensuring the right of everyone to a favorable environment, guaranteed by Art. 42 of the Russian Federation's Constitution is directly related to protecting the environment from economic and other activities' negative impacts.

A noticeable trend in Russia's environmental development is expanding the practice of using new information technologies to ensure environmental protection.

To achieve effective environmental development, the principles of law and indicators are essential to assess the environment's quality. The principle of the priority of public interests ensures, on the one hand, the adoption of measures aimed at curbing environmental pollution, preventing, and minimizing environmental risks. On the other hand, the said principle stimulates the development of innovative methods of protecting a favorable environment, which is especially important in the development and modernization of the digital state. It determines the need to analyze the Smart City program's implementation, one of the trends

\footnotetext{
${ }^{1}$ Corresponding author: vakula2004@yandex.ru
} 
of ensuring a favorable environment in urbanized areas and formulate sound proposals for improving the mechanism for ensuring a favorable environment in the Smart City program.

\section{Materials and method}

The basis of the regulatory framework for the study was the Constitution of the Russian Federation, Federal Law of January 10, 2002, No. 7-FZ "On Environmental Protection," and the positions of the Constitutional Court of the Russian Federation indicated in the Decree of March 5, 2013, No. 5-P, dated July 1, 2014, No. 20-P, October 13, 2015, No. 26-P, March 30, 2018, No. 14-P, Resolution dated June 28, 2012, No. 1256-O; March 5, 2014, No. 496$\mathrm{O}$ and others.

We analyzed strategic international documents and national legal acts, in particular: Revision of World Urbanization Prospects. United Nation Department of Economic and Social Affairs (2018); Draft final document of the UN Conference on Housing and Sustainable Urban Development (Habitat III) (2016), Decree of the President of the Russian Federation of May 9, 2017 No. 203 "On the Strategy for the Development of the Information Society in the Russian Federation for 2017 - 2030" and the Resolution Of the Russian Federation Government dated April 15, 2014 No. 316 "On the approval of the state program of the Russian Federation "Economic development and innovative economy," the Order of the Ministry of Construction and Housing and Utilities of Russia No. 777/pr "On the approval of methodological recommendations for the synchronization of activities implemented in within the framework of state programs of the constituent entities of the Russian Federation and municipal programs for the formation of a modern urban environment, with activities in the field of ensuring the availability of the urban environment for people with limited mobility, digitalization of the urban economy, as well as activities within the framework of the national projects "Demography", "Education", "Ecology", "Safe and quality highways," "Culture," Small and medium-sized businesses and support for individual entrepreneurial initiative" (2019), the Order of the Ministry of Construction, Housing and Utilities of the Russian Federation No. 924/pr "On Approval of the Methodology for Assessing the Progress and Efficiency of Digital Transformation of Urban Economy in the Russian Federation (IQ of cities)" (2019), Concept of the project of digitalization of urban economy" of Smart City," approved by the order of the Ministry of Construction and Housing and Utilities of the Russian Federation No. 866/pr (2020), the Resolution of the Government of Moscow No. 349-PP "On approval of the State program of the city of Moscow "Smart City" (2011), the Resolution of the Government of Moscow No. 597-PP "On intellectual transport system of the city of Moscow" (together with the "Regulations on the intelligent transport system of the city of Moscow") (2017), the Resolution of the Government of the Russian Federation No. 149 "On the development, establishment and revision of environmental quality standards for chemical and physical indicators of the state of the environment, and on the approval of regulatory documents in the field of environmental protection, establishing technological indicators of the best available technologies" (together with the "Regulation on the development, establishment and revision of environmental quality standards for chemical and physical indicators of the state of the environment") (2019), the Passport of the national project "National program "Digital Economy of the Russian Federation" (approved by the Presidium of the Council under the President of Russia for Strategic Development and National Projects (2019), the Passport of the Federal project "Formation of a Comfortable Urban Environment" (approved by Minutes No. 3 of the meeting of the project committee on the national project "Housing and Urban Environment" (2018). We also analyzed the monitoring results of atmospheric air in Moscow for the period 2019-2020. 


\section{Results}

\subsection{Improvement of organizational and legal measures to ensure a favorable environment.}

The system of state measures to ensure the constitutional right to a healthy environment presupposes the existence of duties and powers assigned to public authorities. These include the obligation to protect human rights (Art. 2 of the Constitution of Russia), the obligation to ensure environmental protection, the prevention and elimination of the consequences of human-made accidents and disasters, the obligation to ensure the principle of the priority of public interests, including through the legal regulation of relations in environmental protection and ensuring environmental safety, and the right to interact with the population and take into account the opinion of citizens when locating objects, economic and other activities of which may harm the environment.

Despite the multiplicity of elements included in the content of the right to a healthy environment, the public interest is the one that unites them. The principle of public interest in environmental protection and ensuring environmental safety was designated in the positions of the Constitutional Court of Russia as a priority and determining the constitutional responsibility of public authorities for the preservation of nature and the environment, which necessitates legal regulation aimed at compulsory adoption of measures to contain environmental pollution, prevention and minimization of environmental risks.

The Federal Law "On Environmental Protection" defines the general features of the principle of responsibility of both state authorities of the Russian Federation and its entities and local authorities for ensuring a favorable environment and ecological safety in the relevant territories when exercising the powers assigned to them by these and other federal laws in the relations concerning the environmental protection.

Accordingly, significant attention is paid to assessing the state of the environment at the state level, and as a result, the trends of environmental policy are being improved. In particular, one of the significant innovations was the new edition of Art. 114 of the Constitution of Russia supplemented the powers of the Government of Russia with such issues as the implementation in the Russian Federation of a unified socially-oriented state policy in environmental protection (subsection "b" Part 1) and the implementation of measures aimed at creating favorable conditions for the life of the population, reducing the negative impact of economic and other activities on the environment, preserving the country's unique natural and biological diversity (subsection 5, part 1).

At the present stage of development, ensuring a favorable environment is especially relevant for large cities, which are centers of attraction for the population. According to UN forecasts, in 2050 , about $68 \%$ of the world's population will be living in urbanized areas. Currently, this figure is $55 \%$, and there are about 4.2 billion urban residents in the world (in 1950, there were only 751 million).

Considering that similar trends are observed in the Russian Federation - the number of urban agglomerations is growing and, accordingly, the number of urban residents, there is an objective need to transition to modern technologies for managing urban infrastructure. Many scientists and practitioners pay attention to the importance of digital technologies for implementing programs aimed at sustainable development of territories $[1,2,3,4,5]$, emphasizing the need to improve the system of urban management. One of these areas for improving the system of urban management is the Smart City program. 


\subsection{Implementation of the "Smart City" concept in Russia is the path to the sustainable development of urban areas and providing a favorable environment for the population.}

In world practice, Smart City programs have been successfully vertically and horizontally integrated into social life for over 20 years and are actively supported by the population. In 2016, at the UN Conference on Housing and Sustainable Urban Development, issues related to Smart City programs were raised. The importance of ensuring through a set of measures to improve the quality of life of the population, organizational and legal support of environmental safety, and environmentally sustainable urban development through the digitalization of various spheres of the city's life was highlighted. The need to develop standards that determine the direction of development and criteria for the "Smart City" was also noted.

These aspects were considered in the foreign practice of forming Smart City programs [6, $7,8,9,10,11]$. They implement two main functions carried out through digital technologies - control over the urban environment's quality state and environmental components' protection from negative influences. The balanced development of these functions is an ideal option for ensuring environmental safety in urbanized areas.

In particular, through digital technologies, monitoring atmospheric air indicators is provided, and prompt response processes to deviations from standard values are optimized. A real-time operational control system has been formed in many cities to predict and monitor natural and anthropogenic factors' environmental impact.

Digital technologies have significantly increased the attractiveness of urban agglomerations for the population due to the comfort of the environment, which is provided, including due to tested various models for the development of the "Smart City" concept.

In Russia, the "Smart City" concept is one of the directions of the national project "Digital Economic of the Russian Federation", which recently began to be introduced into a new urban development model focused on a comfortable urban environment.

As part of the implementation of the concept of sustainable development of urban areas, the Smart City programs are characterized by improving citizens' quality of life by various digitalizing areas of the urban economy and creating an environmentally friendly urban environment. At the same time, the interconnection of measures implemented within the framework of state programs of the constituent entities of the Russian Federation and municipal programs for the formation of a modern urban environment, with the national project "Ecology," the Federal projects "Clean country" and "Preservation of unique water bodies" suggest through a particular set of measures aimed at ensuring environmental protection and ecological safety, to realize the right of everyone to a healthy environment, proclaimed as a principle in the Stockholm Declaration on Environment and Development in 1972, and also as a guaranteed right of citizens following the Constitution of Russia.

To form a unified approach to the formation of the urban environment, the Ministry of Construction of Russia approved the requirements for smart cities (Smart City standard), a set of mandatory and additional solutions that consolidate the standard list of services recommended for implementation. Besides, a bank of solutions for "Smart Cities" was also created, which is proposed to guide the formation of "Smart City" programs for various territories. The solutions' description contains links to implement programs that indicate implementation, goals and objectives, their main parameters, and achieved effects. Simultaneously, there are no recommendations on differentiated approaches to smart cities' development based on the implemented projects in the bank of analysis.

At the same time, it should be noted that the methodology for assessing the effectiveness of the digital transformation of urban economy when calculating the IQ index of cities uses only virtual indicators, such as the "readiness of the city" to use the service or "availability" for its use, and the presence of an online air monitoring system characterized by such an 
indicator as "the degree of ensuring environmental safety and the level of attractiveness of the city for the residence of citizens", which is not accompanied by either the normative establishment of the gradation of the specified degree, or the quantitative characteristics of this indicator.

The development of the manufacturability of urban infrastructure in the interconnection of the federal projects "Smart City" and "Digital Public Administration" could be more environmentally friendly if it were not for the lack of administrative and public consensus on this issue. An illustration of the lack of coordination of the actions of the participants in the procedure can be the approval of territorial planning projects, which at all levels does not currently contain effective environmental and legal mechanisms for checking prepared materials for their ecological validity and cannot prevent possible violations of environmental rights during their implementation.

Besides, there is a lack of synchronization between measurable environmental indicators, which are a fundamental part of sustainable development of the territory, and indicators of implementing the Smart City program. Moscow's Smart City program can serve as an illustration of this from a regional perspective. Moscow, which is reasonably listed in the UN global rating "Index of e-government development 2018" as one of the world leaders in digitalization, also did not secure the objective parameters for achieving environmental safety in implementing program activities.

In Moscow, the Smart City program has been implemented since 2011 in many areas. However, to date, the Russian Federation's constituent entity's regulatory legal framework has not fixed the correlation of city authorities' decisions, for example, with a specific level of air pollution identified through environmental monitoring.

In the Moscow Intelligent Transport System, the management of the throughput and loading of the city's street and road network does not have a goal - to reduce emissions from vehicles. Simultaneously, emissions from vehicles in large cities globally have long been recognized as the primary pollutants of the urban environment, and the optimization of traffic flows has a highly positive result in environmental protection. This is confirmed by the information on Moscow's entry into 30 capitals in terms of atmospheric air quality in the world ranking for 2020.

On Moscow's territory, 56 automatic air pollution control stations are currently operating effectively; more than 50 thousand measurement results are received from the stations daily. In the spring of 2020, in the wake of a pandemic, according to data from automatic air pollution control stations, the concentrations of the main pollutants turned out to be up to $60 \%$ lower than in the same period 2019. The carbon monoxide concentrations decreased concerning the typical values by 1.4 times in residential areas, nitrogen -1.8 times.

These monitoring results clearly show that an effective automated tool for collecting and analyzing information in this segment has been created and makes it possible not only to the state indicators of atmospheric air quality but also to evaluate the effectiveness of measures aimed at creating a comfortable, environmentally friendly environment within the framework of the Smart City program.

\section{Conclusion}

Analyzing regulatory legal acts, strategic documents, and the Regulations of the Constitutional Court of the Russian Federation, it can be noted that, in general, there is a positive trend in terms of the formation of measures aimed at ensuring a favorable environment in urbanized areas.

For the sustainable development of urban areas, it is essential to introduce tools to determine a favorable environment's quality. Concerning the digitalization of urban governance, a comprehensive definition of public administration tools has not yet been 
transformed into a set of regulatory legal documents that are consistently implemented by all government branches and pursue the common good as a goal of public interest. In the bylaws, designed to implement constitutional provisions through their practical application mechanisms, there is no specification of environmental and social components. That is why the scientific literature argues that the development of "Smart cities" in Russia is currently hampered by the lack of appropriate national standards for a "Smart city," differentiated taking into account the climatic, economic, and other characteristics of the regions of the country $[16,17]$. Besides, the indicators of the favorable environment for the population and the methods for assessing environmental safety are still not defined.

The principle of the common good, that is, precisely the public interest, should be a decisive factor in the formulation of criteria and indicators to introduce new technologies when creating a comfortable urban environment.

\section{References}

1. N. D. Vershilo, Laws of Russia: experience, analysis, practice, 6, 18-21 (2017)

2. S.N. Bobylev. The world of new economy, 3, 90-96 (2017)

3. A.O. Inshakova, and E. I. Inshakova, (Eds.): CRFMELD 2019, LNNS 110

4. O.L. Krasavchikova, Russian Law Journal, 2 (1993)

5. N.V. Danilova, Russian Journal of Legal Research, 3 (2015)

6. E.B. Weiss, AUILR, 8(1) (1992)

7. T. Ishida, K. Isbister (eds.), Springer-Verlag Berlin Heidelberg, 1 (2000)

8. E. Tranos, D. Gertner, The European Journal of Social Science Research, 25(2) (2012)

9. E.A. Sukhova, M.A. Alkova, Russian Justice, 5 (2020)

10. C. Harrison, B. Eckman (Eds.), IBM. J., 54, 4 (2010)

11. S. Paroutis, M. Bennett, L. Heracleous, Technological Forecast. Soc. Change., 89(2014)

12. M.M. Brinchuk, Journal of Russian Law, 9 (2008)

13. A.A. Babich, Electronic Supplement to the "Russian Law Journal", 2 (2020)

14. K.V. Makarenko, V.O. Loginovskaya, Bulletin of SUSU. Series, "Computer technologies, control, radio electronics", 19(3) (2019)

15. I.V. Makarevich, (2019) Sustainable Development of Science and Education,. 3

16. G.F. Ruchkina, S.G. Pavlikov, Yurist, 10 (2020)

17. O.A. Romanova, Lex Russica, 3 (2020) 